\title{
LA CIUDAD Y EL Río COMO PAISAJE GEOHISTÓRICO Y SU PROYECCIÓN EN EL ÁMBITO EDUCATIVO
}

\section{José Fernando Gabardón de la Banda}

\section{RESUMEN}

El análisis de la dimensión temporal del espacio se convierte en uno de los pilares primordiales de la investigación educativa en el área del conocimiento del Medio Social y Cultural, al dotar al factor geográfico de un contenido histórico, pasando a ser un sujeto vital en la comprensión del entorno en que vivimos. De esta manera el análisis geohistórico de una ciudad puede ser una experiencia vital en la formación espacial y temporal en el ámbito de los ciclos superiores de la Educación Primaria y en Secundaria, como es el caso que proponemos del río Guadalquivir con respecto de la ciudad de Sevilla.

Palabras clave: Geohistoria, tiempo histórico, Didáctica de la ciudad histórica, dimensión temporal del espacio.

\section{TITLE: THE CITY AND THE RIVER AS GEOHISTORIC LANDSCAPE AND ITS PROJEC- TION IN THE EDUCATIONAL CIRCLES}

\section{ABSTRACT}

An analysis of the temporal significance of space has been converted into one of the fundamental pillars of educational research in the subject area of Natural and Social Sciences, by providing the geographical factor with historical content, and becoming an essential subject in the understanding of the environment in which we live. So that the geohistorical analysis of a city may be an essential experience in the spatial and temporal training at the upper stages of Primary and Secondary education, as is the case which we propose on the Guadalquivir river with reference to the city of Seville.

Keywords: Geohistory, historical time, Teaching the historical city, temporal significance of space.

Correspondencia con el autor: José Fernando Gabardón de la Banda. < fgabardon@ceuandalucia.es > Centro de Estudios Universitarios Cardenal Spínola CEU. Original recibido: 3I-0I-14 Original aceptado: 03-06-14 


\section{El análisis geohistórico del paisaje en la investigación educativa: El paisaje como producto histórico}

El paisaje como espacio percibido, no ajeno a la realidad cotidiana del alumno, está siendo uno de los pilares actuales de la Didáctica de Ciencias Sociales. Jaume Busquet perfila su impronta en estos términos: El paisaje no es un objeto nuevo en la enseñanza; forma parte de los centros de interés vinculados tradicionalmente al conocimiento del medio social y natural. Por otra parte, ha sido un recurso educativo con un papel importante en los movimientos de renovación pedagógica mediante la promoción del trabajo de campo y la relación con el entorno. Sin embargo, el concepto de educación en paisaje es relativamente reciente y responde a la reformulación actual del concepto del paisaje. La incorporación de las dimensiones perceptiva y social en el estudio del paisaje en la escuela debería contribuir a superar el distanciamiento que suele producirse entre el fenómeno paisajístico y los alumnos. A consecuencia de dicho distanciamiento, el paisaje es siempre algo ajeno, que forma parte de la realidad exterior, una postal para ser contemplada y estudiada, pero no vivida. El gran reto de la educación en paisaje es conseguir que el paisaje sea algo vivido y experimentado por los alumnos y alumnas, algo que sientan como suyo y que comprometa su actitud como ciudadanos (Busquets, 1996). De esta manera la lectura del paisaje se inserta en el objetivo primordial de la adquisición de las nociones espaciales en el proceso educativo, Lo recalca Busquets: La dimensión perceptiva es una consecuencia lógica, por una parte, de las capacidades y limitaciones de nuestros sentidos en la observación del paisaje, que nunca es idéntica en dos personas, $y$, por otra parte, del papel de filtro que ejercen nuestros valores $y$ características personales (cultura, edad, género...) en toda apreciación del paisaje. Las actividades sobre la dimensión perceptiva del paisaje en la escuela son una oportunidad para el desarrollo de la personalidad del alumnado; en primer lugar, porque favorecen la aprehensión de las propias limitaciones y posibilidades, al tiempo que promueven el desarrollo de una actividad personal crítica y a la vez tolerante; en segundo lugar, porque promueven la conciencia de la subjetividad y de complejidad de conocimiento (Busquets, 2010). ¿Desde qué perspectiva podemos abordar el análisis del paisaje? Al mismo tiempo como señala Antonio Gómez Ortiz el paisaje, el medio o entorno, en sentido amplio o restringido, y de manera explícita o implícita, han estado siempre presente en la escuela, ante todo en el aprendizaje de ciertas materias, como Geografía y Ciencias Naturales (...).

El paisaje no es solamente un producto espacial, sino a la hora de su comprensión debemos de incluir una dimensión temporal, y en este sentido es también un producto histórico, por lo que como señala Xavier Hernández (20 I I) el estudio del 
paisaje también se convierte en un poderoso recurso para el estudio de Historia. La tradición didáctica en cuanto a estudio de la dimensión histórica del paisaje está mucho menos desarrollada que en Geografía. Sin embargo, uno de los obstáculos a la hora de analizar el carácter histórico del paisaje ha sido, sin duda alguna, la tendencia a una constante dicotomía entre los estudios geográficos e históricos en el ámbito de las ciencias sociales en España, tanto en las universidades como en los estudios meramente científicos (Gómez Mendoza, 2008).

La génesis de la Geohistoria marcará una nueva orientación a la hora de analizar la dimensión temporal del paisaje, que, partiendo de las tesis de los Anales de Braudel, será definida por José Luis Orella, uno de sus mayores defensores, como la ciencia que tiene por objeto el estudio dinámico entre una sociedad del pasado y la estructura geográfica que la sustenta, y a la que se unirán las aportaciones metodológicas en el análisis del hecho histórico de Marc Bloch y Lucian Febvre. De esta manera, el análisis geohistórico nos permite relacionar tiempo y espacio, que son los verdaderos pilares de la didáctica de las ciencias sociales, superando el distanciamiento que había sido característico. El análisis geohistórico huye de los fundamentos positivistas, basándose primordialmente en la aplicación del tiempo histórico en el ámbito espacial, con el objetivo de contextualizar el proceso evolutivo de un paisaje, como consecuencia de la respuesta al asentamiento del ser humano sobre el medio natural. De esta manera, el factor geográfico se convierte en un factor histórico más, probablemente el punto de partida de todo el proceso evolutivo de una sociedad, ya que esta depende de su capacidad de respuesta ante el medio y del aprovechamiento de los recursos naturales que este contenga. Así lo subraya el geógrafo Eduardo Martínez de Pisón (2009): Los paisajes son rostros que revelan formas territoriales, formas que expresan estructuras geográficas y ecológicas, modeladas por usos históricos, por puestas en rendimientos de los espacios disponibles..., además, la mayor parte de nuestros paisajes son productos históricos sobre un cuadro o un potencial natural; sus formas documentan hoy el peso de nuestra cultura sobre su espacio como archivos a escala territorial.

\section{Un modelo geohistórico en la investigación educativa: el río y la ciudad}

El río es un elemento que estructura el territorio y el paisaje, a la vez que constituye un vector de diversos factores, un recurso para los sistemas bióticos y sociales, y un fundamento de nuestro imaginario paisajístico común. Surgen de ellos los llamados paisajes fluviales, paisajes con carácter propio, al otorgarles 
el río un fuerte distintivo. Dupuis lo define como el paisaje en cuyo origen y dinámica el río es el elemento principal. El valor de los paisajes fluviales han sido potenciado en los últimos años con la aprobación de la Directiva Europea de aguas (2000/60/CE) del año 2000 y su incorporación al derecho español en diciembre de 2003, que define un nuevo modelo en la planificación y gestión del agua en los países de la Unión Europea, y en la que no pasa desapercibida la calidad de los paisajes fluviales. Posteriormente, en marzo de 2008, ha entrado en vigor el Convenio Europeo del Paisaje (2000) que pondera los aspectos de conservación y educación.

No cabe duda que los tramos fluviales urbanos son potentes recursos educativos, ya sea en el ámbito educativo formal como en el ciudadano, aunque no han sido tratado adecuadamente en el ámbito educativo: Sin embargo, en las ciudades fluviales españolas son escasos los programas educativos o culturales que aprovechan este potencial para desarrollar aprendizaje social, cultural, científico y tecnológico o educación ambiental, y cuando existen lo hacen desde una perspectiva marcadamente naturalista del entorno o comercial del elemento agua. El desconocimiento del río ha sido una constante en el ámbito docente, que, como se resalta en algunos estudios recientes, como el de Agustín Cuello Gijón (2010) en la Universidad de Sevilla, que pone de manifiesto la existencia de obstáculos y dificultades para el uso educativo de los ríos en las ciudades, obstáculos que en la mayoría de los casos se atribuyen a la escasa convicción y actitud del profesorado, alimentada por una deficiente formación inicial y permanente, y una rígida estructura de tiempos y espacios en los centros escolares. A pesar de todo el potencial educativo de los ríos al paso por las ciudades, la ciudadanía parece estar muy alejada de los ríos y sus problemas, siendo el desconocimiento de los ríos, y su significado para la ciudad, casi absoluto. La presencia en libros de texto, en los saberes e intereses del profesorado o en la experiencia de los jóvenes, niños o niñas es escasísimo o de débil incidencia. (Cuello Gijón, 20l I).

Tradicionalmente el río ha formado parte de los diseños curriculares en el ámbito de la Geografía Física, en especial su fisonomía, tanto por su morfología natural como por su papel de soporte físico de la vida humana. Serán los geomorfólogos los pioneros en el estudio de los grandes ríos, que introducen la noción de sistema fluvial a gran escala. Pero será desde los estudios interdisciplinares, desde la Geografía Física y la Edafología a la Ecología, la Geografía Humana y la Hidrología, los que abrirán nuevos enfoques, surgiendo el enfoque sistemático al proponer la geografía soviética el concepto geosistema en los años 60 y 70 . En la década de los años 80 aparecerá un nuevo concepto, la Hidrosfera. 
Muy insertada estaría en el ámbito epistemológico la Teoría General de Sistemas. En 1952 los geógrafos soviéticos dejaron de considerar a la Naturaleza como un obstáculo inerte para la sociedad humana y comienzan a otorgarle un trato preferente en el ámbito ecológico. A partir de 1965, los geógrafos rusos desarrollarán la noción de ECOSISTEMA, a la que se unirán las aportaciones de J. P. Gerasimov sobre las interacciones entre el aspecto natural y el espacio social que conformaran una nueva ciencia, con los objetivos planteados por la Teoría General de Sistemas; el paisaje, percepción de un sistema, es el resultado de la interacción e interrelación de dos subsistemas: el natural y el social. Esta visión sistemática es el resultado del trabajo de Georges Bertrand, geógrafo francés que redescubre la Geografía como una disciplina integrada entre los estudios de paisaje y el medio ambiente.

La relación entre la sociedad humana y el río ha dejado una peculiar fisonomía en el paisaje: Los cursos de agua han definido las redes geográficas, los paisajes-ejes de los hombres: aprovechamiento, captaciones, conducciones, pueblos, caminos, limites, obstáculos, vados, puentes, reglamentaciones, usos, posesión de bienes (...) Su necesidad, su distribución y regulación han desarrollado técnicas y hasta culturas propias, implantadas en el paisaje mediante pozos, galerías, norias, aljibes, presas, canales... (Martínez de Pisón, 2009). Se ha insistido en muchas ocasiones cómo las primeras civilizaciones nacen en el entorno de importantes redes fluviales, como fueron los casos de Egipto, Mesopotamia, China, la India, o el Valle del Po, al permitir que algunos grupos de cazadores y recolectores se asentaran definitivamente en un territorio, pasando de nómadas a sedentarios. La acción antrópica en la ordenación de los medios productivos, especialmente en el análisis de las sociedades agrarias, ha sido constante en la investigación científica, teniendo una amplia proyección en los diseños curriculares educativos, especialmente desde tres ámbitos primordiales, el río como fuente de energía (la llamada energía hidráulica), el río como de vía de navegación, y el río como abastecedor del agua. La degradación del río por los usos urbanos, industriales y agrícolas dio lugar al despertar de una conciencia de protección medioambiental, objeto de análisis de la Geografía Ecológica, que no ha pasado desapercibida en los diseños curriculares de los últimos años.

En la actualidad se ha ido asentando la concepción del río como parte integrante del legado patrimonial en la construcción de la identidad cultural de una sociedad. Recordar el valor cultural de un río supondría esforzada labor, con un exhaustivo trabajo de investigación antropológica, pero sí podemos resaltar algunos aspectos que nos pueden ayudar a la hora de abordar nuestra propuesta de investigación 
educativa. De esta manera, el río en algunas sociedades se convierte en un elemento de identidad religiosa, bien como benefactor de la vida, como podemos apreciar en la sociedad egipcia, bien convertido en una deidad, como el caso del río Ganges en el ámbito de la cultura hindú, o incluso como causa de la fundación de una sociedad con vínculos que la unen a la tradición mitológica. Al mismo tiempo la percepción del rio ha sido un referente en la imaginación poético/ artística en nuestra cultura, desde una simbología de la muerte, como en el caso de las coplas manriqueñas, a la visión idealizada de los románticos, la mirada luminosa de los impresionistas, de la mano de Sánchez Perrier y la escuela de Alcalá de Guadaira etc. El paisaje ribereño siempre atrajo a pintores y escritores por la omnipresencia visual y acústica del agua en movimiento, por su luz especial o por su gama cromática. Esta visión subjetiva del río ha llegado a nuestros días bajo el término de fluviofelicidad, acuñado por uno de los ideólogos de la Nueva Cultura del Agua, Javier Martínez Gil (2010), definido como el placer intenso que se produce al entrar en contacto con el medio fluvial, con el río y con todo aquello que le acompaña.

A la hora de configurar un diseño curricular en torno al río podemos encontrar múltiples variantes, de ahí su potencial educativo, hasta seis grupos concretos:

- Río como hábitat para la diversidad biológica: el río natural.

- Personas y hechos a lo largo del tiempo: el río vivido y sentido.

- Uso y aprovechamiento del río y la riqueza del agua: el río explotado.

- Los problemas ambientales, las soluciones dadas y los restos pendientes: el río maltratado y el río protegido.

- Los paisajes del río en el tiempo y en el espacio: el río cambiante.

- El diálogo río ciudad y el diálogo río-territorio: el río complejo.

Desde una perspectiva de análisis temporal del espacio urbano, el eje de los contenidos en el ámbito histórico del río y la ciudad está marcado por dos hechos fundamentales: el cambio del cauce histórico del río y la configuración de la estructura urbana como conquista espacial del ser humano sobre su cuenca. Las ciudades, como modelo de asentamiento humano, son enclaves estratégicos de dominio territorial, por lo que a la hora de concebir su identidad debemos partir de la base de sus condicionantes físicos, siendo el abastecimiento del agua su elemento clave, de ahí que los ríos, al ser la mayor parte de las ciudades enclaves 
fluviales, sean vitales en la configuración histórica de una urbe. De este modo, el río se convierte en uno de los factores básicos para comprender la configuración de cualquier núcleo de asentamiento humano, especialmente a la hora de comprender el devenir evolutivo de cualquier urbe, traducida en la lucha constante entre los grupos humanos y el propio río en un proceso claro de humanización del territorio, convirtiéndose así el río no sólo en abastecedor de agua, sino en una vía primordial para las redes comerciales, e incluso en un agente modelador de la morfología del propio territorio, por sus continuos desbordamientos y las consiguientes fases de canalización. De ahí que el río se convierta en un factor histórico de primer orden en el estudio del proceso histórico de los asentamientos humanos. Subrayamos las palabras de la profesora Ana María Rojas Eraso ( 1999): La relación entre la construcción de la ciudad en torno a la presencia de un río ha sido una constante histórica. No existe independencia entre la selección geográfica del lugar y la búsqueda del buen abastecimiento y consumo de agua. Por lo tanto, la historia que se inicia con la fundación de un conjunto urbano siempre va paralela a la historia de la transformación del espacio que contiene el cauce y la ronda del río. Los accidentes geográficos del cauce del río asumirán la condición de ser huellas permanentes en la textura de la estructura espacial de la ciudad.

A la hora de analizar el río como factor geohistórico de una urbe debemos analizar como punto de partida dos elementos primordiales:

- Aquellos factores físicos del propio río que pueden incidir en la evolución morfológica del espacio humanizado.

- La capacidad de respuesta de la sociedad sobre el río, que se traduce en la interpretación del río como recurso en tres ámbitos:

- El río como fuente de energía

- El río como vía de comunicación

- El río como abastecedor de agua.

En función de la acción antrópica sobre el río, la urbe irá incorporando obras de ingenierías como puentes (que permiten unión de núcleos surgidos a ambas orillas del cauce fluvial), avances del espacio urbano sobre la ribera del río (ampliación del espacio urbano), labores de canalización, entubamientos e incluso desvíos del cauce, en un afán de frenar las constantes inundaciones, o la instalación de puertos fluviales con una total remodelación de su ribera fluvial. 
Se pueden proponer tres fases básicas en el proceso evolutivo del espacio geográfico analizado (Tabla I):

- Paisaje Fluvial Natural. Corresponde a una primera fase de adaptación antrópica, siendo el río el factor predominante en el modelo de asentamiento, delimitándose el llamado cauce histórico, o cauce natural del río, en el que el ser humano no ha intervenido. Concierne en cierta forma a los llamados modelos preurbanos, donde se han situado sociedades agrarias con una presión demográfica escasa. En esta fase se producen frecuentes inundaciones que destruyen en muchas ocasiones todos los ámbitos del hábitat humano, y que se intentan paliar con defensas de una ingeniería muy rudimentaria. Al mismo tiempo, el río ya se utiliza como fuente de energía, los famosos molinos, como vía de navegación, como redistribuidor de mercancías, se crean puertos, e incluso para abastecimiento de agua.

- Paisaje Fluvial Seminatural. En este modelo las sociedades humanas empiezan a intervenir en el río, aunque sigue permaneciendo el cauce histórico. No obstante, con la Revolución Industrial se inicia un periodo de conquista territorial de los espacios fluviales al desbordarse más allá de las murallas el tejido urbano, a la vez que se construyen nuevos puentes, y se amplían los espacios portuarios, etc.

- Paisaje Fluvial Antrópico. Correspondería ya la fase de humanización del río, en la que el cauce histórico ha sido completamente modificado, e incluso se han abierto nuevos cauces no naturales. Se desarrollaran ya en espacios de intensa urbanización, llegando a producirse una degradación del río.

\begin{tabular}{cccc}
\cline { 2 - 4 } & Acción Antrópica & $\begin{array}{c}\text { Modelo de } \\
\text { asentamiento }\end{array}$ & $\begin{array}{c}\text { Modelo } \\
\text { socioeconómico }\end{array}$ \\
\hline $\begin{array}{c}\text { Paisaje Fluvial } \\
\text { Natural }\end{array}$ & Pervive el cauce histórico & Preurbano & Sociedades agrarias \\
\hline $\begin{array}{c}\text { Paisaje Fluvial } \\
\text { Seminatural }\end{array}$ & $\begin{array}{c}\text { Modificación inicial del cauce } \\
\text { histórico }\end{array}$ & Urbano. & Sociedades industriales \\
\hline $\begin{array}{c}\text { Paisaje Fluvial } \\
\text { Antrópico. }\end{array}$ & $\begin{array}{c}\text { Transformación del cauce } \\
\text { histórico. Nuevo cauce } \\
\text { artificial. }\end{array}$ & Megalópolis & $\begin{array}{c}\text { Sociedades } \\
\text { postindustriales }\end{array}$ \\
\hline
\end{tabular}

Tabla I. Fases básicas en el proceso evolutivo del espacio geográfico fluvial 
Una de las disciplinas primordiales del análisis geohistórico es sin duda alguna la Arqueología del Paisaje, que fue estudiado por el profesor Orejas (199I): es algo comúnmente aceptable que el paisaje es una construcción cultural y, como tal, acumulativa, que ha generado un verdadero palimpsesto que conserva por doquier huellas, improntas o marcas más o menos ocultas de todo su periodo evolutivo (...) Desde esta perspectiva podemos decir que todo el paisaje se puede investigar desde la metodología arqueológica como podemos hacer con cualquier artefacto. Se trataría de considerar el paisaje como un documento que permite leer en lo espacial la dimensión temporal, por lo que, como bien afirma Schlögel (2007), se trata de recuperar el punto de vista espacial complementándolo con el vector temporal a la hora de interpretar. Como subraya Fernando Amores (20 I0), más allá de pretender interpretar el paisaje el paisaje como una secuencia temporal de acontecimientos, priorizamos el discurso espacial al entender que el paisaje relata la historia. Abordamos, por tanto, la reconstrucción del paisaje histórico desde una metodología de lectura del paisaje con una triple dimensión como es la lectura espacial, temporal y temática.

Un recurso esencial a la hora de abordar el análisis temporal de la dimensión espacial del paisaje lo constituye el mapa geohistórico. No sólo responde a una representación meramente espacial de un territorio, sino que, al mismo tiempo, proyecta su dimensión temporal, al presentar una evolución diacrónica del territorio. En este caso, como puntos de referencia estarían el cauce del río y el propio núcleo poblacional con el que se va interrelacionando. El mapa geohistórico tiene un matiz diferenciador al tradicional mapa histórico, complementando aún más a éste, como bien refiere Xavier Hernández Cardona (20I I): También existen mapas con voluntad explícita de mostrar aspectos del pasado, son los mapas históricos. Estos mapas intentan mostrar un determinado espacio o lugar en un periodo concreto. Son útiles en tanto nos informan sobre la organización política, sobre cuáles eran las principales vías de comunicación, siendo su manejo una constante desde finales del siglo XIX. Sin embargo, su utilización presenta problemas evidentes. En general (...) se obvian los factores geográficos (...) en consecuencia, la no relación entre el territorio y los factores históricos pueden alejarnos de la percepción científica de una determinada cuestión. Y es que en el mapa geohistórico el factor predominante debe ser el factor geográfico, y en el caso analizado debe ser el río, aunque sin dejar atrás evidentemente la acción antrópica que ha ido teniendo lugar a lo largo del proceso evolutivo. Al mismo tiempo, el mapa geohistórico de un entorno urbano favorece aún más la compresión de su entorno cotidiano, al concebir el papel que ha jugado la relación entre la sociedad y su medio natural. 
PAISAJE FLUVIAL NATURAL

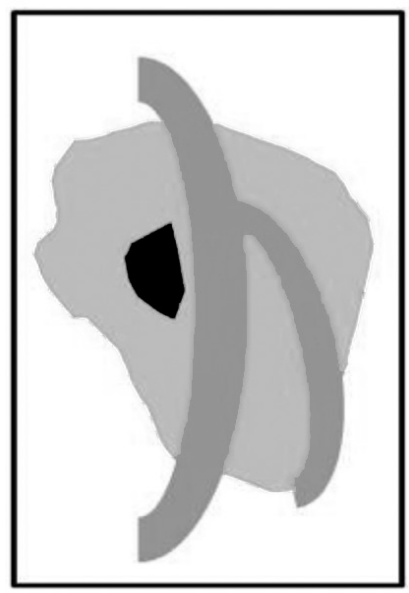

PAISAJE FLUVIAL SEMINATURAL

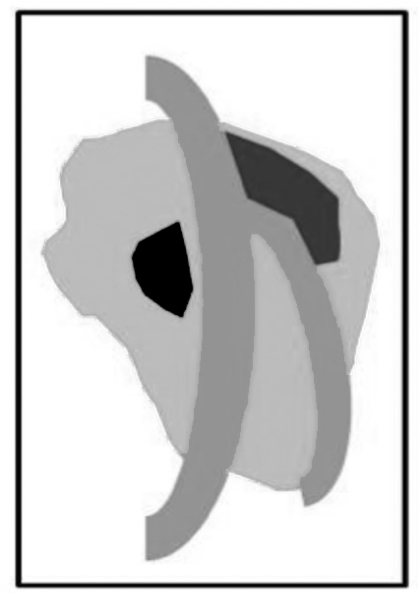

Valle fluvial

Cauce

Zona arbórea

Núcleo poblacional
PAISANE FLUVIAL ANTRÓPICO

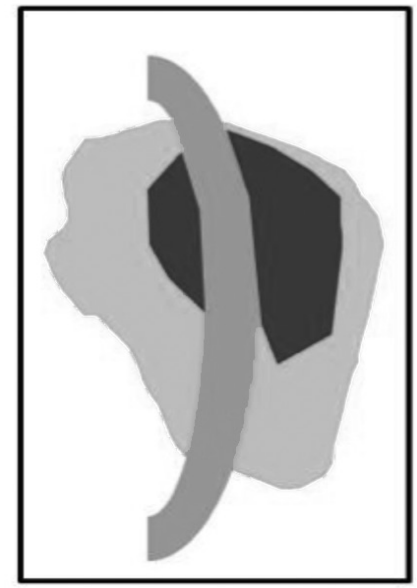

Figura I. Fases de la acción antrópica de un río.

Todos los paisajes fluviales en el ámbito urbano no han evolucionado de igual manera, ya que la acción antrópica cambia en función de las circunstancias técnicas y económicas. Es ahí donde se fundamenta el valor educativo del análisis geohistórico al aplicar el tiempo histórico en el espacio geográfico.

De esta manera el análisis geohistórico del río en los ámbitos urbanos se convierte en un instrumento vital en los ciclos superiores de Primaria y Secundaria, no así en Infantil, donde no se da aún una interiorización de la dimensión espaciotemporal. Al mismo tiempo, este análisis se inserta en la línea perceptiva del espacio cotidiano, por lo que, en los ámbitos locales de las ciudades fluviales, puede llegar a ser un instrumento vital en el proceso de comprensión de la evolución de la ciudad en relación con el río, incluso ayudando a despertar la conciencia crítica, al permitir establecer una reflexión sobre la distribución espacial de los recursos y el desequilibrio social. 


\section{Un proyecto de selección de contenidos curriculares del análisis geohistórico: Sevilla y el río Guadalquivir}

\section{I. Los factores fisicos estimulantes del rio como factor histórico}

Leandro del Moral (1997) destaca dos factores físicos primordiales del río que van a tener su proyección en el ámbito antrópico:

$\left.1^{\circ}\right)$ Su navegabilidad. Sevilla se ubica en el extremo superior del estuario del Guadalquivir, manteniendo una relación con su río condicionada secularmente por el progresivo deterioro de las condiciones de navegación. El estuario del Guadalquivir se desarrolla a lo largo de una llanura de pendiente prácticamente imperceptible, formada por materiales aluviales que se vienen sedimentando a razón de entre I y $2^{\prime} 5 \mathrm{~mm} /$ año en los últimos milenios. La falta de pendiente y la naturaleza deleznable de estos materiales, unido a la violencia de sus avenidas, motivan el carácter sinuoso e inestable de su cauce, que aguas abajo de Sevilla se dividía en diversos brazos de trazado meandriforme.

$\left.2^{\circ}\right)$ Su régimen de avenidas y su influencia sobre la ciudad. A consecuencia de la irregularidad de su régimen, con un módulo que ronda los $185 \mathrm{~m}^{3} / \mathrm{s}$, y estiajes en que desciende por debajo de los $10 \mathrm{~m}^{3} / \mathrm{s}$, el Guadalquivir experimentaba crecidas de $5000 \mathrm{~m}^{3} / \mathrm{s}$ y $9000 \mathrm{~m}^{3} / \mathrm{s}$ con periodos de recurrencia de 5 y 100 años respectivamente. En estas ocasiones, las aguas alcanzaban su altura de 7 y 10 metros sobre el nivel del mar, amenazando con diferente intensidad a una ciudad que en gran parte se extiende sobre el propio llano de inundación, y cuyas áreas más deprimidas, como la Alameda, se sitúan a la cota 4,30 m.

En estas condiciones, la relación de Sevilla con el río ha estado marcada por la lucha secular por la preservación de la navegabilidad y por la defensa frente a la amenazas de inundación.

\subsection{La formación geológica del valle del Guadalquivir.}

La primera propuesta didáctica a la hora de abordar el análisis de un río es el análisis de su formación geológica, que en el caso del río Guadalquivir iría desde el Terciario, caracterizado por la delimitación de un gran estuario, al Pleistoceno, en que el estuario va perdiendo espacio en favor de una amplia sedimentación que se prolongará en las subsiguientes fases del Holoceno hasta llegar a la fase actual. 

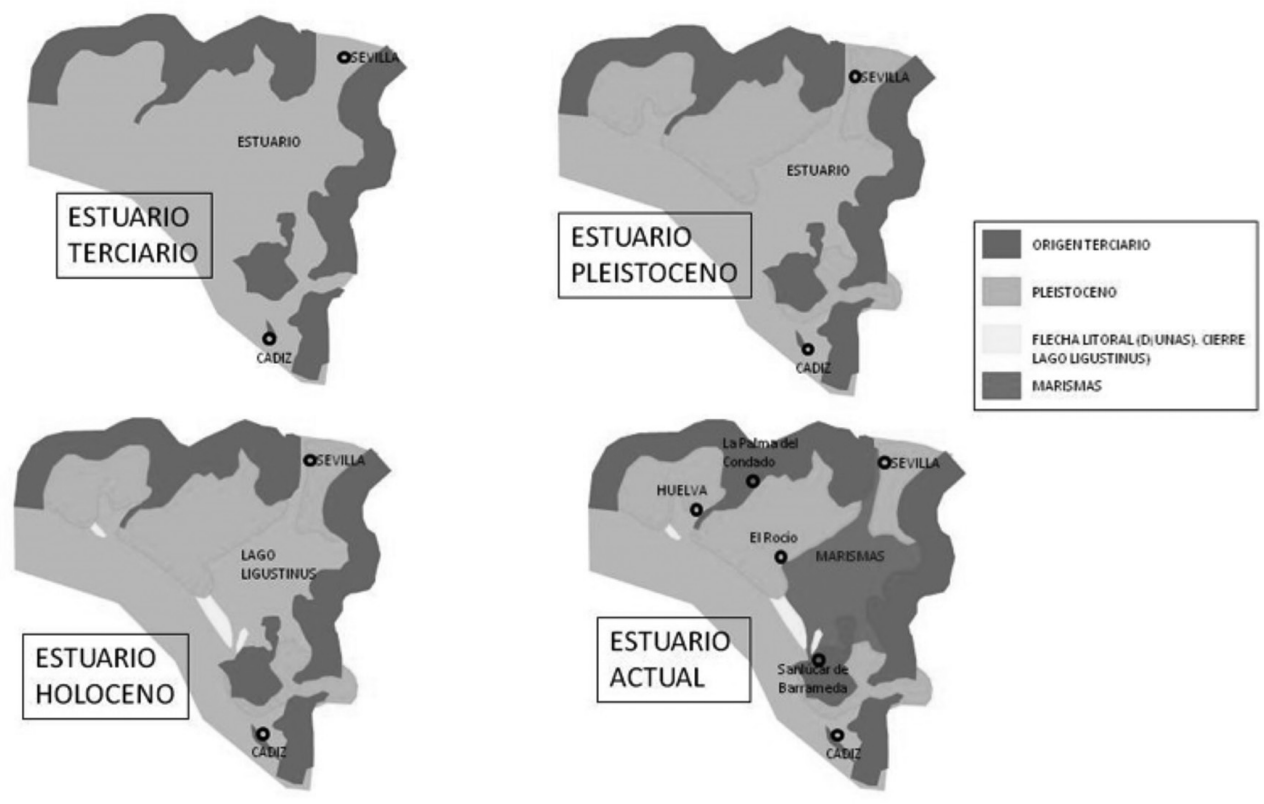

Figura 2. Evolución geológica del estuario del Guadalquivir

3.3. El paisaje fluvial natural. Del asentamiento tartesio al periodo califal.

En esta fase se pueden distinguir las fases históricas prerromana, romana, visigoda y califal, en la que todavía no hay una amplia impronta de la acción humana sobre el río.

- El asentamiento prerromano. Durante el periodo prerromano podemos distinguir las siguientes características:

I. El río Guadalquivir en el periodo fenicio-tartesio responde todavía a una fase de sedimentación, en la que el asentamiento de Spal es de carácter insular.

2. Ubicada en las terrazas de la orilla izquierda, la Spal del periodo tartesio se establece en los sitios que hoy todavía presentan cotas más elevadas en el casco antiguo. El primer centro urbano era insular, rodeado al Este por un antiguo brazo del Guadalquivir que discurría a lo largo del actual prado de Santa Justa, en el cual desembocaba el arroyo Tagarete, y al Oeste por otro brazo del río. 
3. El término Spal es una derivación de población de palafitos, por el modelo de asentamiento que presentaba el primer núcleo poblacional, dominado por un terreno pantanoso e inhabitable en su primera fase histórica.

4. Será el carácter navegable del río y su ubicación estratégica lo que convertirá el primitivo asentamiento en un núcleo comercial, a raíz de la fundación de los fenicios, siguiendo el modelo que ya habían utilizado en la ciudad de Gades. Su proximidad a las minas de Aznalcóllar y a las tierras de la vega interior determinará su evolución posterior.

5. Cabe mencionar el desarrollo cultural que experimenta en este periodo el Aljarafe, cuyo legado arqueológico más importante lo representa el santuario fenicio del Carambolo.

- El río de Híspalis:

I. En la etapa romana la situación geográfica del Bajo Guadalquivir estaba delimitada por el lago Ligustino y el Golfo Tartésico, en el que la ciudad de Híspalis era un núcleo insular.

2. La situación del río Betis y la ciudad de Híspalis fue recogida por la literatura grecolatina. Estrabón hace la siguiente descripción: Las orillas del Betis son las más pobladas; el río puede remontarse hasta una distancia aproximada de I.200 estadios, desde el mar hasta Kordyba, e incluso hasta algo más arriba. Las tierras están cultivadas con gran esmero, tanto las ribereñas como las de sus breves islas. Hasta Híspalis, lo que supone cerca de 500 estadios, pueden subir navíos de gran tamaño; hasta las ciudades de más arriba, como llipa, solo pequeñas.

3. Un río navegable. Los romanos desde muy pronto vislumbraron la extraordinaria potencialidad del valle bético. Durante la primera etapa de dominación romana, el Baetis seguía siendo una corriente de agua que desembocaba a la altura de Coria del Río en una inmensa albufera marítima (Doñana), y con pocas facilidades para una navegación continuada más allá de Alcalá del Río (Sevilla). La situación cambiará a partir de la etapa de Julio César (siglo I a.C.), cuando la región se llena de establecimientos, las denominadas colonias. La navegabilidad parcial de su cauce, al menos con barcazas hasta Córdoba, o la amable topografía de terrazas y vegas ayudaron a convertirlo en una vía comercial.

4. Recientes hallazgos en el norte y en el sur de la ciudad de Híspalis, han conformado la existencia de un brazo secundario del Guadalquivir, tanto por el descubrimiento de una factoría de salazón de pescado en la actual plaza de 
la Encarnación, del siglo I. d.C., como por los restos encontrados en la Puerta de Jerez en las intervenciones del año 2004, a raíz de las obras del metro, que ya indican la existencia de un barrio portuario en lo que en su momento fue la confluencia del arroyo Tagarete y el Guadalquivir.

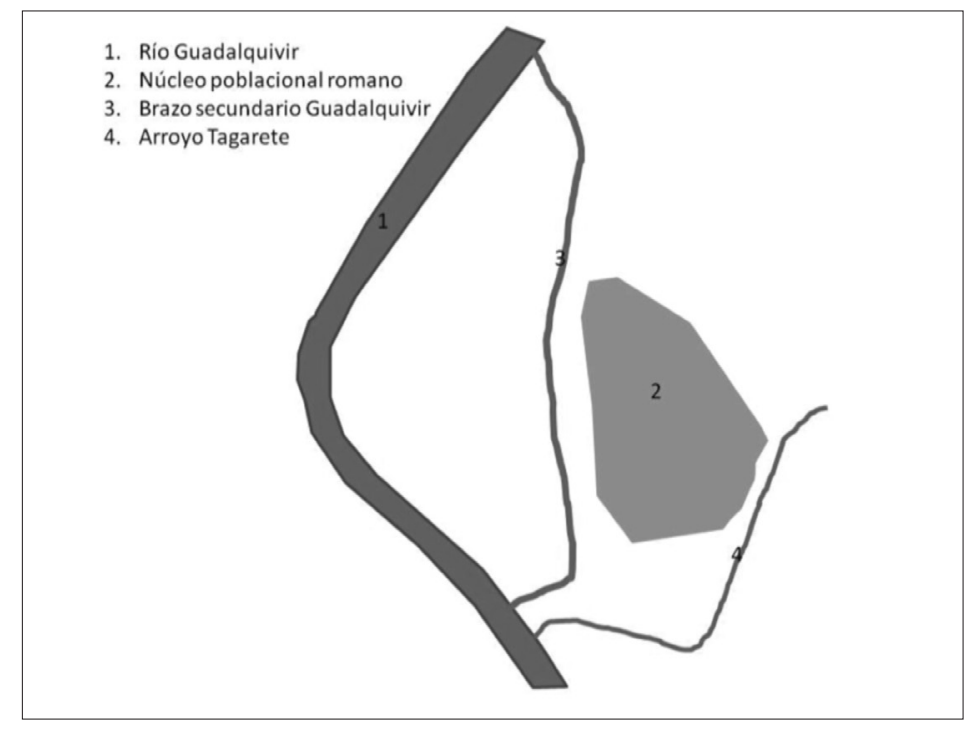

Figura 3. Paisaje del Río Guadalquivir en la etapa romana.

- De la ciudad visigoda a la ciudad califal. En este amplio periodo que abarca desde el siglo $\mathrm{V}$ al $\mathrm{X}$ d.C., se distinguen algunas novedades, como son:

I. La ciudad va a heredar la configuración urbana del modelo romano bajoimperial, estando delimitada por una cerca amurallada, entre dos tramos del rio Guadalquivir (el primero hoy desaparecido) y el Tagarete. El núcleo urbano principal está delimitado por el entorno El Salvador-Alfalfa.

2. Entre 7 I I y 1090, Isbilya (Sevilla) se extiende hacia el sur, transformándose en villa árabe, en la que el río bordeaba la sólida muralla al Oeste.

3. Sevilla posee ya en esta etapa un importante puerto, a un centenar de kilómetros de la desembocadura. Los primeros astilleros constan del siglo IX, después de las invasiones normandas que azotaron a Sevilla en el 844. Abd al-Rahman I (822-852) ordenó levantar un arsenal para la construcción de barcos. 


\subsection{El paisaje fluvial seminatural del río Guadalquivir (s. XIII-finales del s. XVIII).}

Desde la etapa de los almohades hasta el siglo XVIII se puede considerar el paisaje fluvial de la ciudad de Sevilla como un paisaje fluvial seminatural, en el que se puede distinguir una acción antrópica inicial. Entre los caracteres fundamentales se puede considerar:

I. El cauce del Guadalquivir estaría configurado como un rio meándrico, en un único cauce, ancho, con proliferación de barras de canal aguas arriba de Sevilla, y divagante en su amplia llanura drenada no solamente por el Guadalquivir, sino también por sus afluentes, los arroyos Tagarete y Tamarguillo, en las cercanías de la ciudad. Además, el Guadalquivir desarrollaba un bosque de ribera en ambos márgenes.

2. Los periodos de inundación son muy amplios, azotando continuamente a la ciudad, con las consiguientes pérdidas humanas y materiales.

3. La navegabilidad del río convierte a la ciudad en un eje principal de comercio.

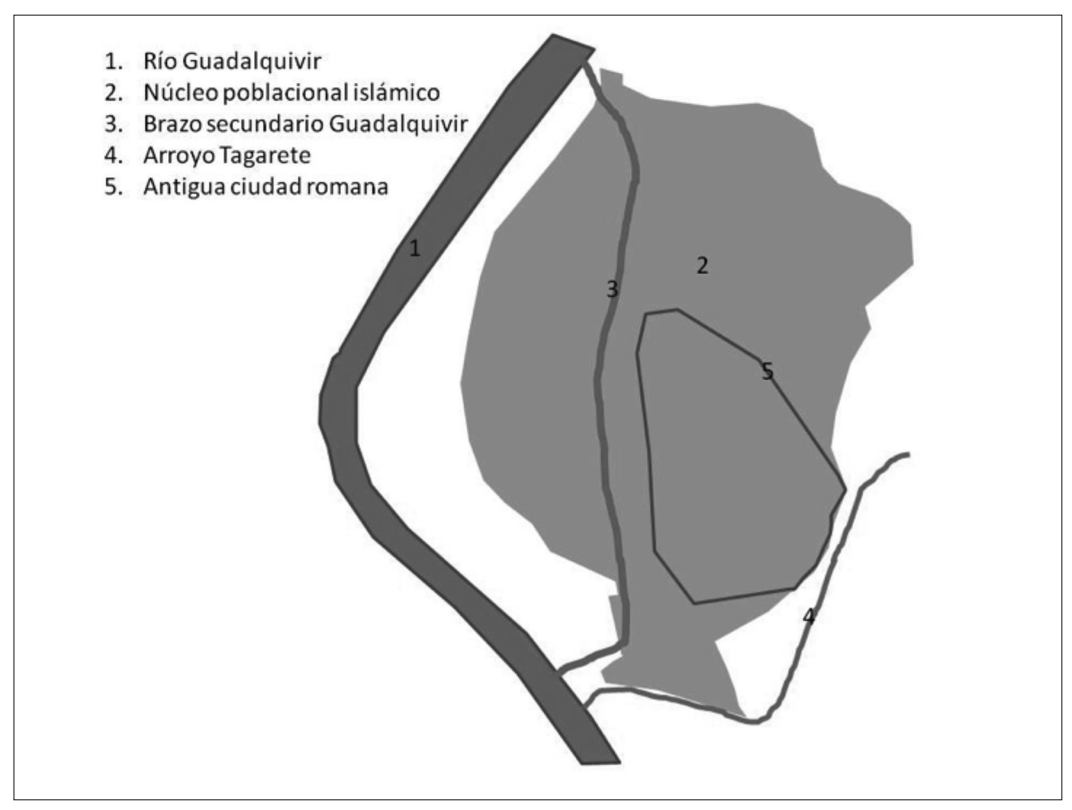

Figura 4. Paisaje fluvial seminatural del Guadalquivir (s. XIII-finales del s. XVIII). 
- El río Guadalquivir en el periodo almohade (/ /47-/248):

I. Los autores árabes presentan el Guadalquivir en algunos aspectos diferentes al de hoy, mucho más amplio, con diferentes brazos en funcionamiento, incluyendo el que cerraba el recinto amurallado heredado del bajo imperio romano por su flanco occidental y que transcurría desde la actual Puerta de la Barqueta al Arenal. El Tagarete corría en superficie, no subterráneo, y formaba parte del sistema defensivo de la ciudad, desembocando en la Torre del Oro.

2. La gran unidad urbana ligada al agua en Isbilya será el puerto, que, como aparece en los testimonios literarios, será considerado uno de los mejores de Al-Andalus.

3. Se construye el Puente de Barcas, que sustituye a un sistema de almadias con cables, a la altura de la actual Cartuja. La construcción del puente se realizó a instancia del Califa Abu Yacub Yusuf el sábado 5 de septiembre de II 7 I.

4. El río abastecía las huertas del entorno de la ciudad, en especial las de los recintos palaciegos. A instancias de una orden de mayo de II84 se reconstruyen los llamados Caños de Carmona, convirtiéndose en uno de los mejores ejemplos de abastecimiento de agua de la historia islámica hispana. Su nacimiento se situaba en los alrededores de la ciudad de Alcalá de Guadaira, en el pago llamado de Santa Lucía. El agua era conducida a Isbilya mediante un complejo subterráneo de largas galerías excavadas en la roca de calcarenita. Un segundo tramo discurría desde la Cruz del Campo al Olivar de la Reina, y de allí al palacio de la Buhaira; el último iba desde el Olivar de la Reina hasta la ciudad y desde allí al Alcázar.

5. Las inundaciones eran frecuentes, especialmente la del año $\mid 200$.

- Una gran ciudad bajomedieval.

I. El recinto urbano sigue prácticamente delimitado por la muralla que había sido levantada por los almohades. Ha surgido la llamada ciudad gótico mudéjar o de las collaciones, encajada entre los ríos Guadalquivir y Tagarete.

2. El río ya tenía en esta etapa una connotación negativa, su régimen torrencial. La fuerte irregularidad de las lluvias, concentradas en determinados periodos del año, hacía que todos los años se produjeran desbordamientos, con dimensiones a veces catastróficas. Este carácter torrencial, al incidir sobre un 
cauce con débil pendiente en el tramo medio, y casi horizontal en el inferior, contribuyó a hacer cada vez más graves las inundaciones, y a generar mayores dificultades a la navegación, por la proliferación de meandros, las alteraciones y colmatación del cauce, etc. En los siglos XIII y XIV se registran las crecidas de 1297, I 302, I 330 y I353. La riada de 1403 fue especialmente desastrosa, desbordando algunas partes de las murallas, y llegando el agua a San Miguel (Plaza del Duque), como así aparece reflejada en la crónica de Enrique III del canciller Ayala. De gran trascendencia será también la riada de 1485, narrada por Andrés Bernáldez.

3. El río Guadalquivir convierte a Sevilla, como señala Collantes de Terán, en un eje económico cuya importancia se irá acrecentando con el incremento de las relaciones comerciales que se generan, tanto en el ámbito interno como en el internacional, como lo menciona el rey Alfonso $X$ el Sabio a mediados del siglo XIII en su General Estoria: Viene a Sevilla cada día navíos desde la mar por el río; e las galeras e naos apuestan fasta dentro en los muros con todas mercancías quantas son en todas partes del mundo, de Tanja, de Ceuta, de Tunex, de Alejandría, de Génova, de Portogal, de Ingratierra, de Pisa, de Lombardía, de Bordeos, de Bayona, de Secilia, de Bayona, de Aragón e aun de Francia vienen ende muchas e de otras muchas partes en allen mar e de tierra de cristianos.

4. La construcción de las Atarazanas durante el reinado de Alfonso $X$ el Sabio convierte a la ciudad en un punto de referencia primordial del comercio, e induce la rehabilitación de la margen izquierda del río.

- El Guadalquivir, un rio puente hacia el Atlántico (Siglo XVI).

I. Tras el descubrimiento de las Indias, y establecida la cabecera del monopolio mercantil con el Nuevo Mundo, el tramo del Guadalquivir que discurre desde la desembocadura de Sanlúcar hasta el puerto sevillano de las Muelas, junto a la Torre del Oro, da un salto cualitativo en su proyección mundial. A decir de Tomás de Mercado, el Guadalquivir pasa de río y puerto fluvial de reminiscencias medievales a convertirse en la principal vía marítima del tráfico atlántico durante doscientos años, además de un centro portuario de primer orden a escala mundial.

2. El puerto es durante la centuria de 1500 a 1600 la principal referencia económica de la ciudad. Sevilla será escenario de grandes hazañas del descubrimiento americano, como las expediciones de Vicente Yáñez Pinzón y 
Diego de Lepe (I499-I500), Cristóbal Guerra (I500), Rodrigo de Bastidas y Juan de la Cosa (I50I-I502).

3. Durante el reinado de Felipe II, se realiza uno de los hitos más importantes del urbanismo del momento, la Alameda, actuación de 1574 a iniciativa del Conde de Barajas, Francisco de Zapata, que transforma una antigua laguna en paseo de álamos blancos, ganado la ciudad un amplio espacio interno. Otra laguna, la de la Pajarería, situada cerca de la Puerta del Arenal, también fue transformada.

4. Como proyección de la actividad comercial se desarrolla en el margen derecho del río la zona llamada del Arenal, con los arrabales ya consolidados de la Carretería, Postigo del Aceite y Puerta de la Mar, la Cestería, Puerta de Triana, y los Humeros, Puerto Real.

5. Ya en el siglo XVI se alude en diversas fuentes a las dificultades para la navegación a causa de los recodos, a veces muy cerrados, la poca profundidad del lecho y escaso caudal del río durante buena parte del año, que trocaban al Guadalquivir en un peligro cierto, por lo que había que transbordar parte de la carga a barcos auxiliares, que si bien incrementaba los costes, ni mercaderes ni navieros protestaban al facilitar el contrabando y burlar las obligaciones fiscales.

- Un río en decadencia (siglo XVII-segunda mitad del siglo XVIII). En este periodo la ciudad no experimenta ninguna expansión de trascendencia más allá de sus murallas, por lo que hereda la morfología del periodo anterior y sigue definida entre los ríos Guadalquivir y Tagarete.

I. Durante el siglo XVII, el río vuelve a inundar Sevilla, concretamente en I6031604; 1608, 1618-1619, 1626, 1633, 1642, 1649, 1683-84, 1691-92 y 1697.

2. Sevilla deja de ser el eje vital del comercio internacional americano con la firma por Felipe V, el 12 de mayo de 17I7, del decreto por el cual la Casa de Contratación se trasladada a Cádiz. Probablemente la causa estaría en que el puerto de Cádiz era mucho más adecuado para el atraque de las grandes naves que realizaban el comercio de Indias. Para llegar a Sevilla las naves tenían que pasar las barras de Sanlúcar, con grandes dificultades de maniobrabilidad, lo cual provocaría grandes naufragios. Además había que cruzar el Guadalquivir, cuyas características de navegabilidad no permitían que los barcos llevasen más de 600 toneladas de cargas. 
3. En torno a las orillas de los ríos sevillanos se instalan las primeras fábricas estatales, como la Fábrica de Tabaco, que en 1757 ya estaba concluida, o la Maestranza de Artillería.

\subsection{Paisaje fluvial antrópico.}

La acción antrópica sobre el cauce histórico del río Guadalquivir comienza ya a partir de finales del siglo XVIII, y en sucesivas fases culminaran a principios del siglo $\mathrm{XXI}$, con el resultado de una amplia humanización del río.

- Los primeros proyectos de transformación del río en la etapa de los ilustrados (finales del siglo XVIII). Durante el siglo XVIII, Sevilla continuaba haciendo frente a las inundaciones. Una primera etapa de inundaciones corresponde a los años I73I, 1736, I739, I740 y 174I. Desde 1748 las crecidas van en aumento, con episodios en los años 1758, I 784 y 1796, que supera las anteriores. De cariz especial fue la de 1786 que afectó al Prado de Santa Justa y Rufina, y luego a la mayor parte de la ciudad, así como a la propia Triana.

Ante las amplias crecidas del río se redactaron una serie de proyectos considerados como el precedente de la transformación del río por la acción antrópica. La Corta de Merlina, junto a Coria (I784-I785), se pone en marcha tras la constitución del Consulado Marítimo y Terrestre de Sevilla en I784, siendo la primera intervención de gran envergadura en el Bajo Guadalquivir, que no solo favoreció la navegación, sino además el rápido desagüe de sus grandes avenidas. La obra fue dirigida por Scipion Perosini, y consistió en la apertura de un canal de algo más de 600 metros de longitud que evitaba un gran meandro a la altura del Coria del Río.

Entre 1778 y 1784 se perfila un proyecto de mejora de navegabilidad del río Guadalquivir por la Sociedad Económica de Amigos del País de Sevilla, precisamente en el mismo año en que se promulgaba el Reglamento del Libre Comercio de América, del que Sevilla se iba a quedar descolgada. Resultó premiado el Proyecto presentado por Don Francisco Pizarro, Maestro de Matemáticas en el Real Colegio de Seminario de San Telmo de Sevilla, y que fue remitido para su informe a Don Antonio de Ulloa, Teniente General de la Real Armada. El 21 de mayo de 1783 es remitido al Rey el proyecto, que lo acoge positivamente, y se comisiona a Don Julián Sánchez Bort el reconocimiento del terreno para la ejecución del plan. 
- Nuevas actuaciones en el río durante el primer liberalismo (|8|4- |840).

I. La ciudad sigue manteniendo el mismo perímetro que en la etapa anterior, marcada por la coracha almohade, y perfilada entre los dos ríos históricos, el Guadalquivir y el Tagarete, aunque ya se esboza el desarrollo de algunos sectores como la Macarena, San Bernardo o Triana.

2. Entre 1825 y 1830 el asistente Arjona comienza a mejorar sectores que se encontraban fuera del perímetro de la ciudad, ordenando el paseo entre la muralla y el Guadalquivir comprendido entre la Torre del Oro y el puente de barcas, y el saneamiento de la Puerta Jerez, donde trazara los Jardines de Cristina, que se pueden definir como el primer desborde la ciudad intramuros, proseguido por los duques de Montpensier con su establecimiento del palacio de San Telmo en 1849.

3. La ciudad sigue sufriendo inundaciones como las de los años 1803,1816 , 182 I, I823, I824, 1835 y 1854.

4. Para dotar de una mejor navegabilidad al río se constituye la Real Compañía de Navegación del Guadalquivir en 1814, mediante la Real Orden de 12 de diciembre de 1814, que autoriza su constitución, y la Real Orden de 8 de agosto de 1815 que aprueba el plan y sus concesiones. Entre sus proyectos se acometería la Corta del Borrego, o también llamada Fernandina (1816), efectuadas en Isla Menor, con un trazado de 1600 metros.

5. La Compañía realiza así mismo una obra de ingeniería característica que quedará en la iconografía de la ciudad: el puente de Isabel II, inaugurado suntuosamente el 2 I de febrero de 1852, y que marcará en el fin de una etapa $y$ el comienzo de otra.

6. El encauzamiento del río Tagarete lo realiza el arquitecto municipal Balbino Marrón en 1849, y consiste en la conducción y entubamiento del mismo por la zona de la Puerta de Jerez. La irregularidad del río fue ya descrita por Mal Lara en 1570, e incluso en el siglo XVIII se intentó diseñar un proyecto de urbanización de la mano de Ignacio Salas, aunque no se llegó a modificar o alterar su cauce. 


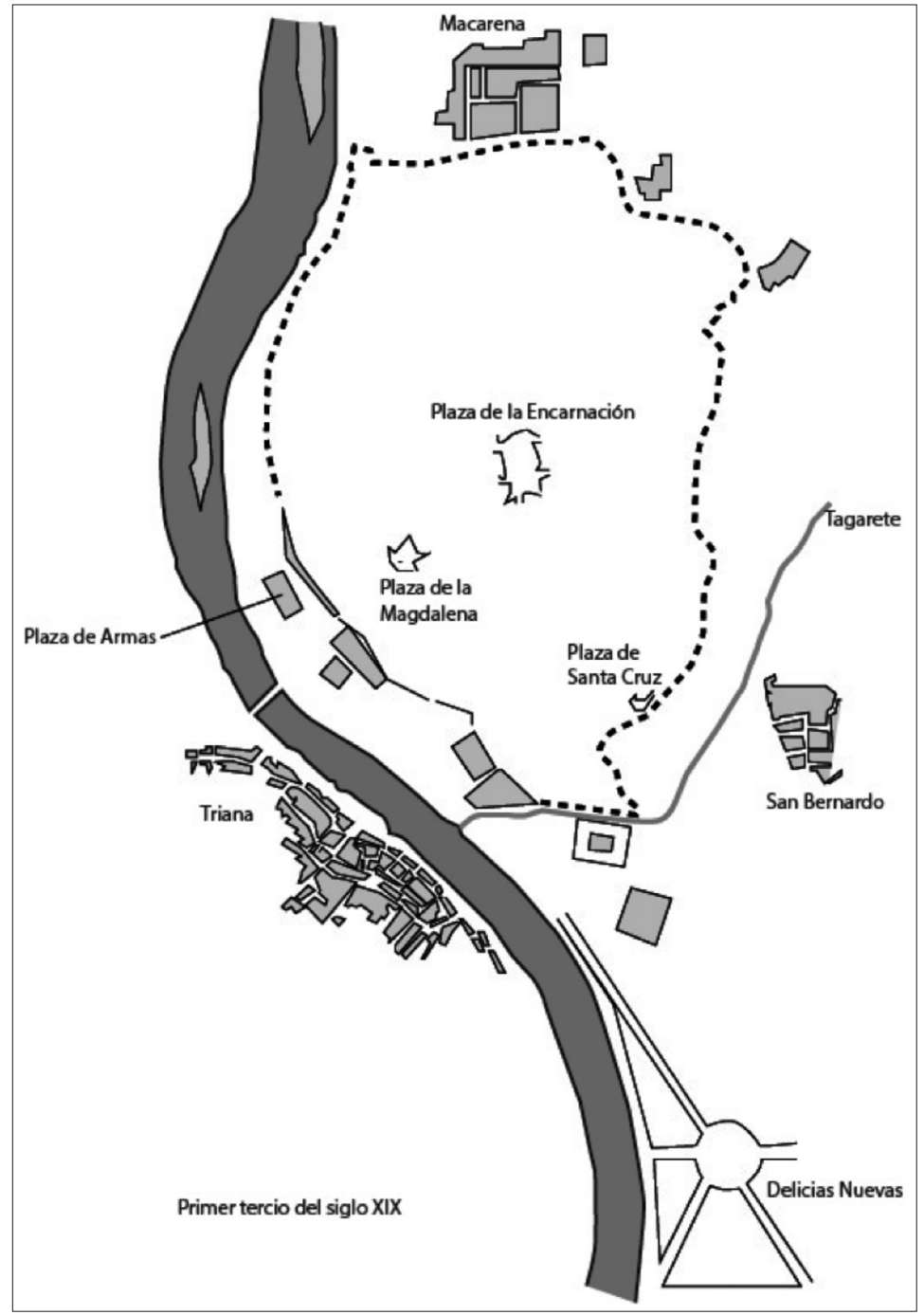

Figura. 5. Paisaje fluvial del Guadalquivir en el primer tercio del siglo XIX

- Un periodo de relanzamiento: el río industrial. El periodo final isabelino (I860- I868).

I. Se produce un cambio sustancial con la construcción en 1859 de la línea de ferrocarril entre Sevilla y Córdoba, cuyo trazado irá paralelo al río a 
raíz del interés de los comerciantes y la propia Diputación sevillana, como así recogerá la Real Orden de 17 de octubre de 1855, disponiendo en el antiguo Campo de Martes, actual estación de Córdoba, como punto de partida. Ello supuso la transformación de la margen derecha del Guadalquivir (Torneo).

2. Se relanza en esta etapa el papel del puerto, concebido como centro de una amplia región y motor de su desarrollo, para lo que se impulsó la creación de una amplia red de caminos y ferrocarriles que sirviera de conexión entre el puerto y los centros de producción. El proyecto dirigido por el ingeniero Canuto Corroza en 1857, inicia actuaciones como dragados, eliminación de bajos y pendientes uniformes, e incluso apertura nuevos cortes.

3. Se intentó aumentar el calado del rio mediante dragados, pero sin éxito, con el desánimo de los comerciantes sevillanos. Pastor y Landero, en I862, presenta un nuevo proyecto, y entre 1863 y 1868 se hará cargo de las obras, abordando las grandes transformaciones que en este momento necesitaba la actividad comercial de la ciudad, con la configuración actual del muelle del puerto histórico, en el antiguo Arenal, al que dota de una zona de servicios de 1376 metros de longitud. Modificó el cauce mediante diques de defensa frente a la Cartuja, las Delicias y San Juan de Aznalfarache.

- El río durante la Restauración (1874-1900).

I. Los planes para la defensa general de la ciudad elaborados entre el último cuarto del siglo $X I X$ y principios del siglo $X X$ dedicaron especial atención al barrio de Triana, ante la indefensión en que se encontraba y los graves daños que le ocasionaban las inundaciones del Guadalquivir. El proceso arranca con la conmoción producida por la gran inundación del 8 de diciembre de 1876. La ciudad se vio retrotraída a situaciones superadas incluso con el antiguo sistema defensivo que conformaban las murallas, siempre que éstas, y sus puertas correspondientes, estuvieran adecuadamente atendidas. Se creó de forma inmediata, como lógica consecuencia, una Comisión Facultativa para estudiar las defensas de la Ciudad contra las inundaciones del Guadalquivir.

2. La obra más significativa del periodo es, sin duda alguna, la Corta de los Jerónimos, iniciada en I860 y concluida en I880. Con ella, tras las de la Merlina y el Borrego, eran ya tres las realizadas en el Bajo Guadalquivir. 
3. En esta etapa surgen una serie de proyectos como los de Talavera $(\mid 88 I)$ y Higgins (1882). El proyecto de Juan Talavera y de la Vega, fechado el 10 de septiembre de $\mid 88 \mathrm{I}$, tiene el mérito de ser el primer planteamiento moderno y global de defensa de la ciudad de Sevilla. Comenzaba planteando, como solución definitiva a la que se había que aspirar, la elevación de la rasante de la ciudad en los sectores inundables, para lo que proponía desviar el arroyo Tagarete desde la Fuente del Arzobispo hasta el Portón de la Reina, donde se uniría con el Tamargillo.

4. En las inmediaciones de la estación de ferrocarril de la Plaza de Armas se instaló el Puente de Alfonso XII, a fin que la línea de ferrocarril Huelva-Sevilla salvara el río Guadalquivir. Fue inaugurado el 15 de marzo de 1880 , pero con el paso el tiempo, el puente quedaría en desuso y sería desguazado.

- Una primera transformación del cauce durante el periodo de Alfonso XIII (I9001929).

I. La alarma social por el peligro de inundaciones, como la del año 1892, y la expectativa de la celebración de la Exposición Hispano Americana, fueron determinantes para la intervención sobre el cauce del rio.

2. En 1903, el director de la Junta de Obras del Puerto, Luis Moliní, redacta un Proyecto general de obras de mejora de navegación de la ría del Guadalquivir y su desembocadura, y del puerto propiamente dicho. Se retoma la idea de Sevilla como centro económico de una región ordenada por el Guadalquivir. Ya anteriormente el ingeniero Sanz Lurumbe había presentado un proyecto contra las inundaciones (1901-1903).

3. Se procede a la apertura de la Corta de la dehesa de Tablada, de seis kilómetros de longitud, una de cuyas obras principales será la construcción de un puente metálico levadizo para comunicar ambas márgenes. Estas obras tomaron la denominación de Canal de Alfonso XIII, y se prolongaron por la mala situación financiera de la Junta de Obras del Puerto, y sobre todo por la Gran Guerra, desde 1913 hasta 1919, provocado un freno a la actividad comercial. No se inauguran hasta 1926, con una nueva reducción de la longitud del Guadalquivir en $4 \mathrm{~km}$, que facilitaba el plan de defensa de Sevilla contra las inundaciones. 


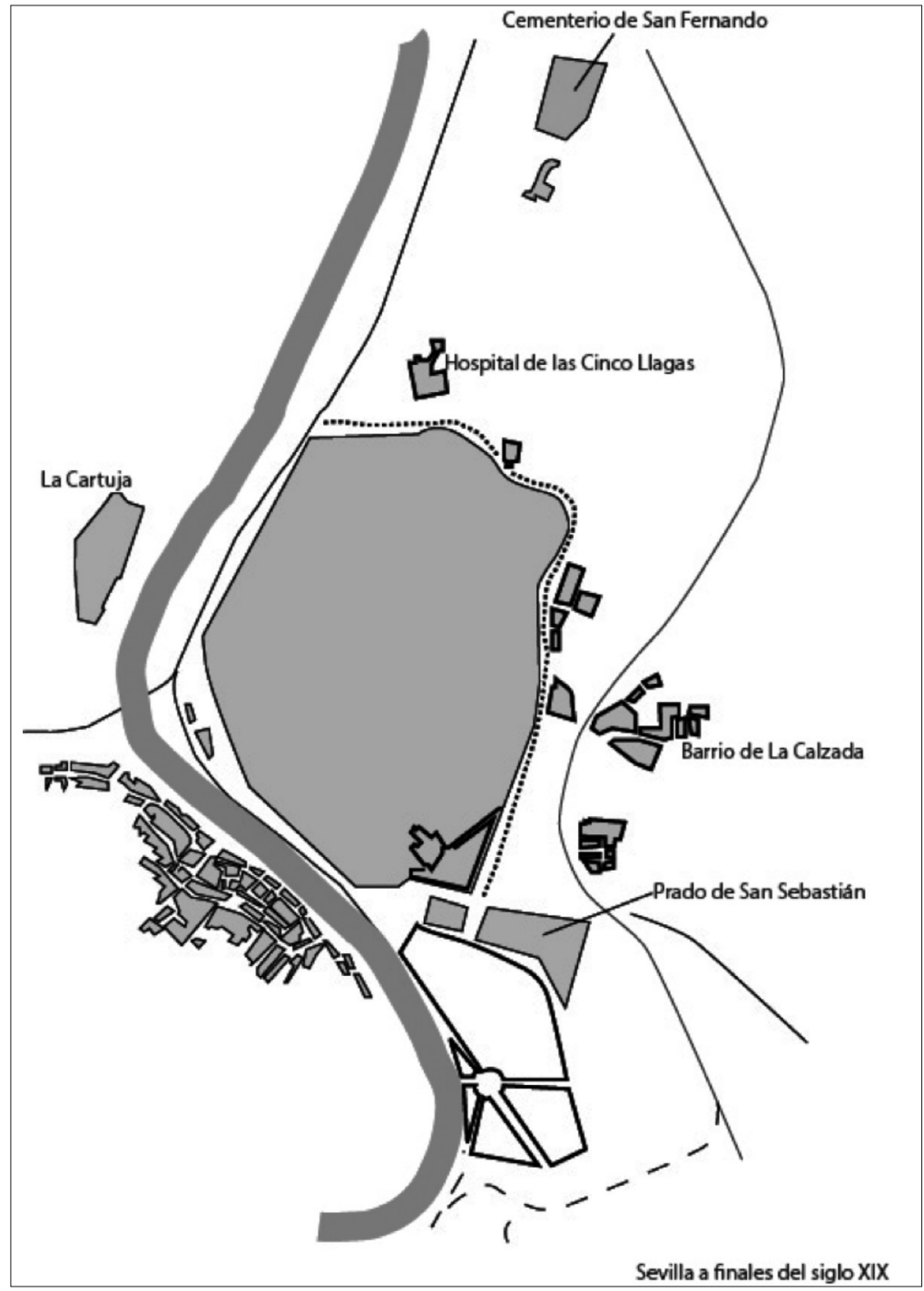

Figura 6. Paisaje Fluvial del Guadalquivir a fines del siglo XIX.

4. Sobre la margen izquierda del canal comienza la construcción de los muelles destinados al servicio de mercancías generales, con una longitud de 800 metros. En la cabecera del nuevo puerto se construye un puente provisto de un tramo central 
móvil para facilitar el acceso de las embarcaciones hasta el Puente de Triana. En la margen derecha, entre el puente de Isabel II y la Torre del Oro, se concluye en 1905 la construcción de un muelle de entramado metálico denominado de Nueva York, pero que terminó siendo demolido por hundirse en varias ocasiones.

5. En abril de 1926 se inauguraban las obras hidráulicas pertenecientes al plan Moliní, que incluían la desviación de los cauces del Tagarete y Tamarguilo al Guadaira.

6. El puente de San Telmo había sido proyectado por el ingeniero José Eugenio Ribera, ganador del concurso de 1920, pero no se inauguró hasta 193I. Se completaría con un puente de hierro que sería conocido con la denominación de Alfonso XIII, cuya longitud era de 175 metros.

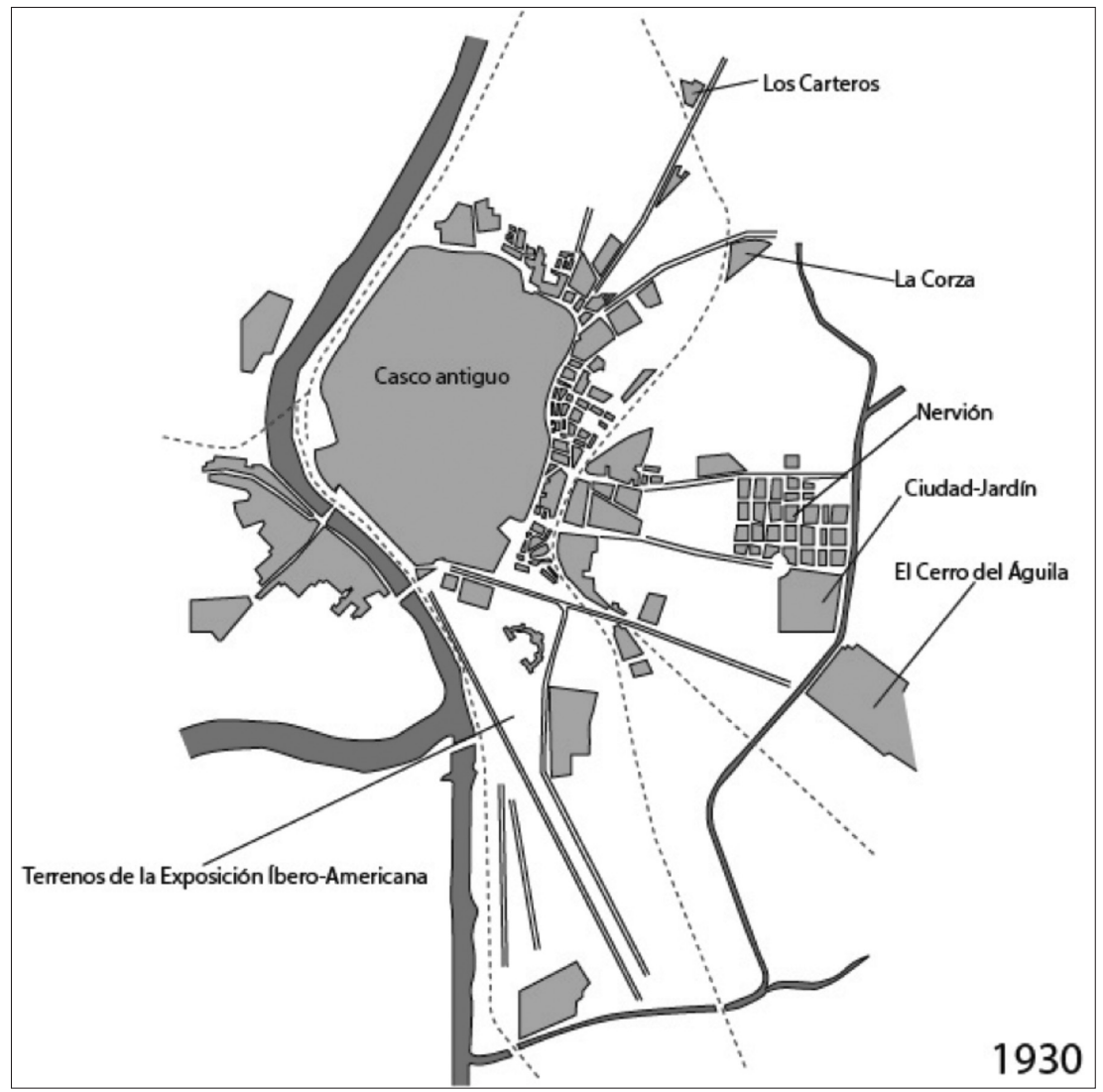

Figura 7. Paisaje Fluvial del Guadalquivir en torno a la Exposición de 1929. 
- El franquismo (1940-1970).

I. A partir de 1948 el río histórico quedó cerrado por el tapón de Chapina, abriéndose un nuevo brazo desde Triana hasta San Juan de Aznalfarache. A ello se uniría la corta de la Vega de Triana y la esclusa de la Punta del Verde. Estas medidas estuvieron cargadas de polémica ya que cercenaban el cauce viejo del río Guadalquivir.

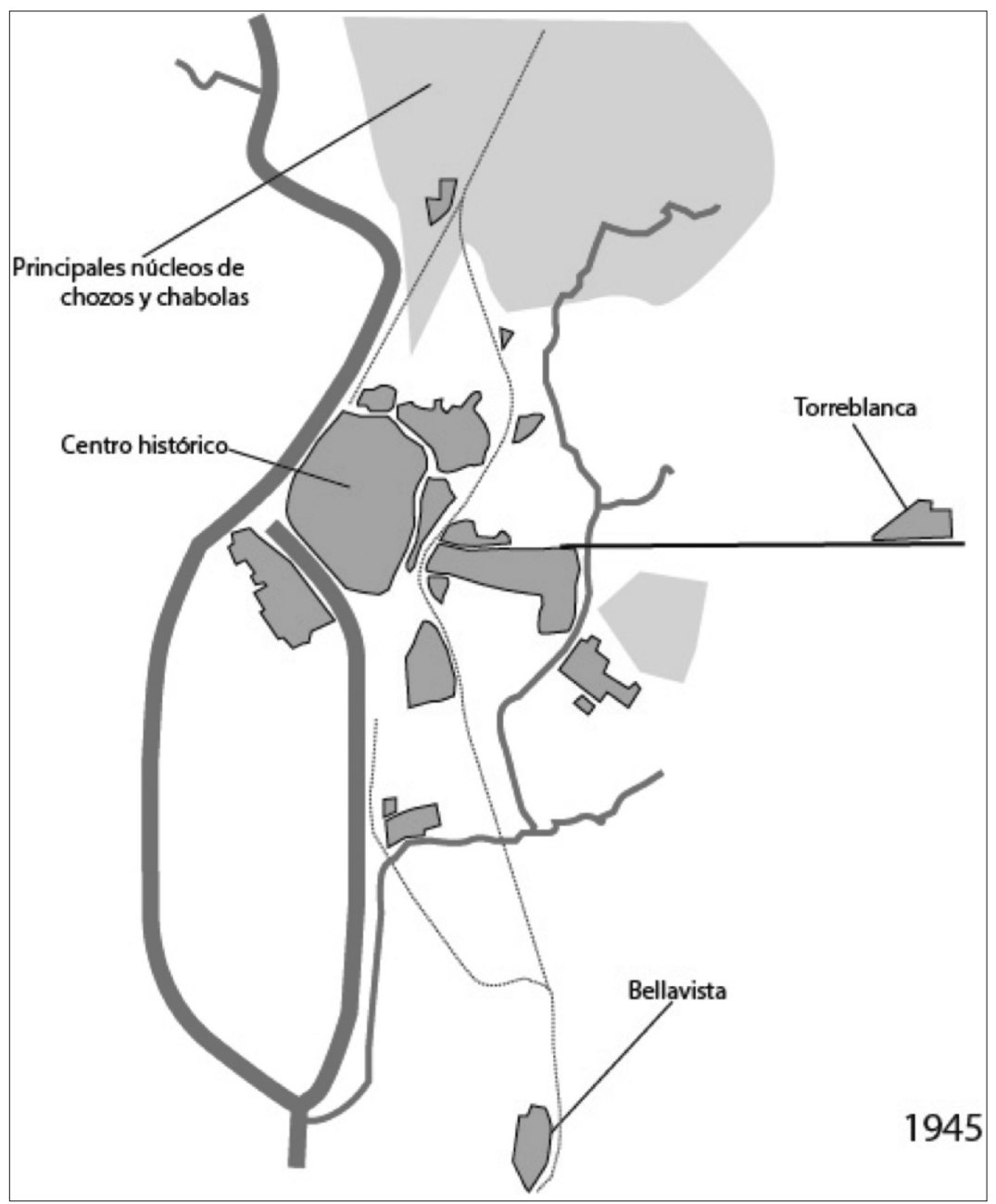

Figura 8. Paisaje fluvial del Guadalquivir en la década de 1940. 
2. La construcción de un nuevo puente sobre la Dársena, el Puente del Generalísimo, establece un punto intermedio de conexión entre el de San Telmo y el del Alfonso XIII. La necesidad de este nuevo puente surge por el desarrollo urbanístico de la margen derecha de la Dársena, y en especial el crecimiento del Barrio de los Remedios, que ya en los años 50 era considerable. Hacia 1956 se realizan los estudios para su construcción, siendo en 1957 cuando Carlos Fernández Casado redacta un proyecto de puente giratorio. La obra será adjudicada a la empresa Dragados y Construcciones, concluyéndose en 1968.

3. El desbordamiento del Tamargillo en 196I provocará el desvío de su cauce, poniendo en práctica el proyecto diseñado por el ingeniero Sanz y Larumbe en 1903, consistente en el desvío del arroyo Tagarete antes de su llegada a la ciudad y unir sus aguas a la del Tamarguillo, en el punto conocido como Puente de Ranilla. Tras las inundaciones de noviembre de I96I, se ejecuta un nuevo proyecto que consistió en desviar el cauce del Tamarguillo aguas arribas de Sevilla, haciéndolo desembocar directamente al Guadalquivir al norte de la ciudad. De esta forma el antiguo cauce quedó seco y con el tiempo se convirtió en una ronda urbana para vehículos llamada Ronda del Tamarguillo.

- En el entorno de la Expo 92.

I. La Corta de la Cartuja tuvo una amplia repercusión urbanística para Sevilla. El río, a la altura de San Jerónimo, al norte de la ciudad, formaba una curva pronunciada con un muro de defensa construido con materiales de insuficiente calidad, por lo que se realizó una nueva corta de seis kilómetros de longitud, sustituyendo el meandro de San Jerónimo a fin de evitar el ataque frontal del río. La conclusión de las obras abrió la posibilidad de ampliar la zona urbanizable en los terrenos de la denominada Isla de la Cartuja, urbanizados con motivo de la celebración de la Exposición Universal de 1992. Al mismo tiempo se reintegraba el cauce histórico del Guadalquivir con la eliminación del aterramiento de Chapina.

2. Se ejecutó un proyecto de encauzamiento del arroyo Tamarguillo, por lo que su antiguo cauce, conocido hoy con el nombre de Ranillas, fue canalizado desde el Aeropuerto hasta su desembocadura en el Guadaira.

3. Durante la Expo se construyeron una serie de nuevos puentes, $\vee$ Centenario (J. Fernández Ordóñez - J. Martínez Calzón); Puente del Alamillo (Santiago Calatrava Valls); Puente de la Barqueta (J.J. Arenas de Pablo) y el puente del Cristo de la Expiración (J. L. Manzanares Japón). 
4. Dos hitos primordiales se desarrollarán en el ámbito del urbanismo de 1992: el Parque Metropolitano del Alamillo y la rehabilitación de la antigua Cartuja de Santa María de las Cuevas.

5. En el año 2003, se elaboró un nuevo proyecto por la Confederación Hidrográfica del Guadalquivir para desviar de nuevo el cauce del arroyo Tagarete más al norte de su situación actual, creando un nuevo trazado que alcanzaría el Guadalquivir a la altura del barrio de San Jerónimo (Sevilla). El proyecto pretende evitar las inundaciones en la zona norte de la ciudad y crear un cauce nuevo de mayor calado y 27 metros de anchura. Ello implicaría la construcción de nueve puentes nuevos, dos para líneas de ferrocarril y siete para carreteras. En el año 2012 la ejecución de las obras se encontraba paralizada debido a la falta de fondos, no existiendo ninguna fecha prevista para su realización.

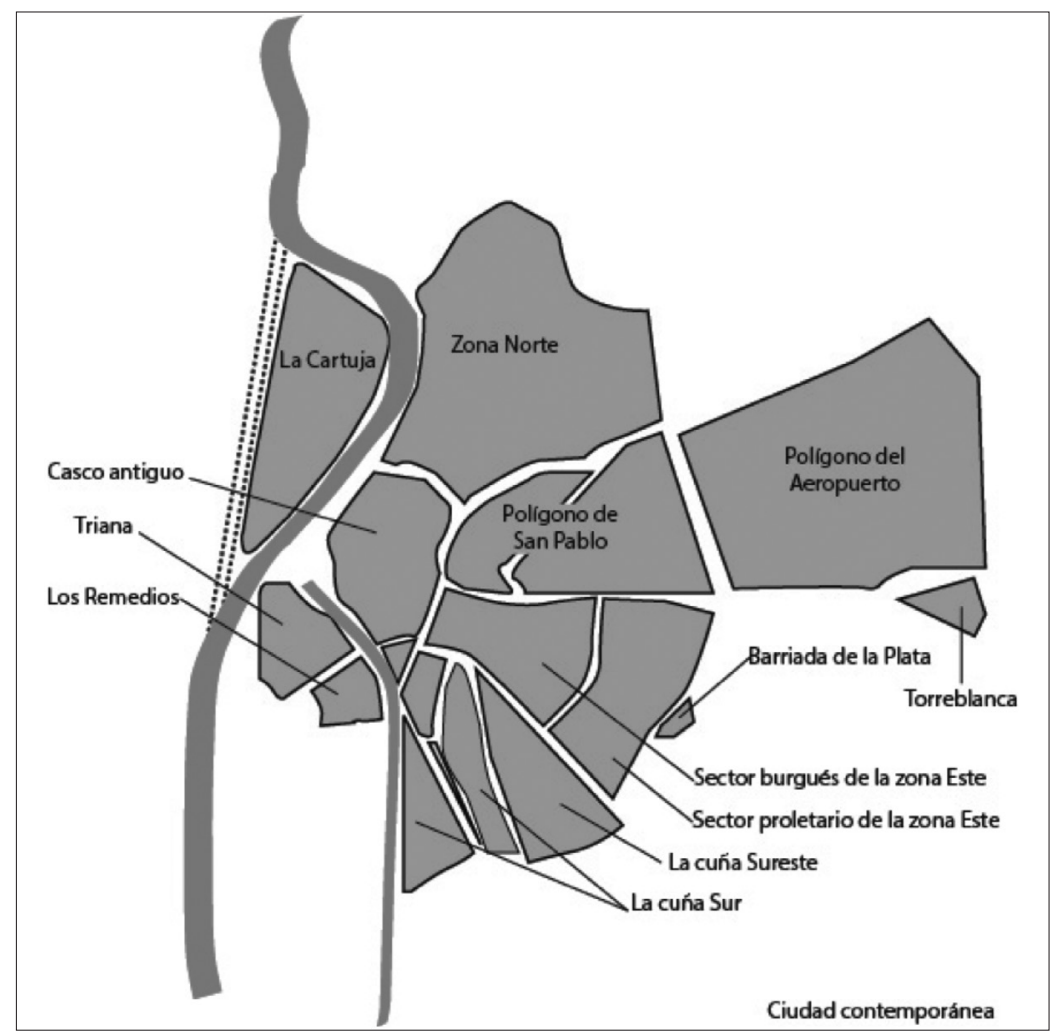

Figura 9. Paisaje Fluvial del Guadalquivir en el entorno de la Exposición de 1992. 


\section{Bibliografía}

Amores, F., Rodríguez-Bobada, M. C. (2010). Reconstrucción del paisaje histórico en el valle del Guadiamar. Primeros resultados y nuevas perspectivas de investigación y difusión. En F. Amores Carredano, De la Tierra al Sol: historia de los paisajes del Guadiamar (pp.88-89). Sevilla: Focus Abengoa.

Busquets, J. ( 1996). La lectura visual del paisaje. Bases para una metodología. Iber: Didáctica de las ciencias sociales, geografía e historia, 9, 53-60.

Busquets, J. (2010). La educación en paisaje: Una oportunidad para la escuela. Iber: Didáctica de las ciencias sociales, geografía e historia, 65, 7-16.

Cuello, A. (2010). Los tramos fluviales urbanos como ámbitos de aprendizaje. Una valoración de su potencial educativo y los obstáculos que plantea su utilización. En M. Junyent Pubill y L. Cano Muñoz (Coords.), Investigar para avanzar en educación ambiental (pp. 63-84). Madrid: Organismo Autónomo Parques Nacionales. Ministerio de Medio Ambiente y Medio Rural y Marino.

Cuello, A. (20I I). Ríos, ciudades y educación en VII Congreso Ibérico sobre gestión y planificación del agua. Talavera de la Reina.

Hernández, F.X. (20I I). Representación e interpretación del espacio. Cartografía. En J. Prats (coord.), Geografía e Historia: investigación, innovación y buenas prácticas (pp. 97-107). Barcelona: Graó.

Martínez, F. J. (2010). Una nueva cultura del agua y de la vida. La experiencia fluviofeliz. Zaragoza: FNCA.

Martínez, E. (2009). Miradas sobre el paisaje. Madrid: Biblioteca Nueva.

Moral, L. (1997). El agua en la organización del espacio urbano: el caso de Sevilla y del Guadalquivir. Documents d'anàlisi geográfica, 31, I I7- 127.

Orejas, A. (199I). Arqueología del Paisaje: historia, problemas y perspectivas. Archivo Español de Arqueología, 64 (163-164), 191-230.

Rojas, A. M. (1999). Pasto, ciudad y río. Una experiencia para el desarrollo metodológico. Bitácora Urbano-Territorial, 3, 27-4I.

Schlögel, K. (2007). En el espacio leemos el tiempo. Sobre Historia de la civilización y Geopolítica. Madrid: Ediciones Siruela. 


\section{Anexo}

A continuación se incluye una serie de referencias de interés sobre el tema, no citada en el texto:

Didáctica del Paisaje.

Benayas, J. y López, C. (2010). Propuestas didácticas para vivir el paisaje. Iber: Didáctica de las ciencias sociales, geografía e historia, 65, 56-65.

Besse, J. M. (20I0). La sombra de las cosas. Sobre paisajes y geografía. Madrid: Biblioteca Nueva.

Feliu, M., Hernández, F. X. (20II). I2 ideas clave: Enseñar y aprender historia. Barcelona: Graó.

Gómez, J. (2007). Geografía e Historia. Encuentros y desencuentros en Francia y en España a lo largo del siglo XX. En A. Cohen Amselem y R. Peinado Santaella, Historia, historiografía y Ciencias Sociales (pp. I0I-I48). Granada: Universidad de Granada.

Sobre el Guadalquivir en la historia

Ruiz , J. L. (2006). Triana y Los Remedios durante el siglo XX: la conformación urbana del sector occidental de Sevilla. Sevilla: Diputación de Sevilla.

Serrano, F. (1989). Historia gráfica del Puerto de Sevilla. Sevilla: Junta de Obras del Puerto.

W.AA. (2006). Los puentes sobre el Guadalquivir en Sevilla. Sevilla: Colegio de Ingenieros de Caminos, Canales y Puertos.

W.AA. (20I I). El agua y Sevilla: abastecimiento y saneamiento. Sevilla: EMASESA.

\section{Agradacimientos}

El autor de este artículo agradece la colaboración de su compañero D. Álvaro Lama Sánchez por la elaboración de los mapas incluidos en las figuras I, 2, 3 y 4, así como al alumno D. Francisco Javier Gaviño Lora en la elaboración de los mapas incluidos en las figuras $5,6,7,8,9$ y 10. 